\title{
High-Throughput Discovery and Evaluation of a General Catalytic Method for N-Arylation of Weakly Nucleophilic Sulfonamides
}

\author{
Joseph Becica,, Damian P. Hruszkewycz, ${ }^{\ddagger}$ Janelle E. Steves, ${ }^{\ddagger}$ Jennifer M. Elward,§ David C. Leitch,* \\ $\neq, \uparrow$ and Graham E. Dobereiner*,† \\ † Department of Chemistry, Temple University, Philadelphia, PA, 19122, United States. \\ ₹ Chemical Development, GlaxoSmithKline, Collegeville, PA, 19426, United States. \\ $\S$ Molecular Design, Data \& Computational Sciences, GlaxoSmithKline, Collegeville, PA, 19426, United States. \\ " Department of Chemistry, University of Victoria, Victoria, BC, V8P 5C2, Canada.
}

\begin{abstract}
Sulfonamides are poor nucleophiles in Pd C-N coupling catalysis, hindering synthesis of densely-functionalized $\mathrm{N}, \mathrm{N}$-diaryl sulfonamide motifs relevant to medicinal chemistry. Through targeted high-throughput experimentation (HTE), we have identified the Pd/AdBippyPhos catalyst system as an effective and general method to construct this difficult to access moiety. In particular, AdBippyPhos is critical for the installation of heteroaromatic groups. Computational steric parameterization of the investigated ligands reveals the potential importance of remote steric demand, where a large cone angle combined with an accessible Pd center is correlated to successful catalysts for C-N coupling reactions.
\end{abstract}

\section{INTRODUCTION}

The sulfonamide functional group, a metabolically-stable hydrogen bond acceptor, is commonly found in biologically active molecules including many active pharmaceutical ingredients. ${ }^{1-4}$ Sulfa drugs such as sulfamethoxazole have been used for decades as inexpensive anti-microbial agents, ${ }^{5}$ while more complex sulfonamides find use as anticancer agents, ${ }^{6}$ antiretroviral agents, ${ }^{7}$ in hepatitis $\mathrm{C}$ treatment, ${ }^{8}$ and in various crop protection methods. ${ }^{9}$

Through our work on GSK8175 (Figure 1), an NS5B inhibitor for treatment of hepatitis $\mathrm{C}, 8,10$ we discovered that efficient access to the $\mathrm{N}, \mathrm{N}$-diarylsulfonamide motif is a significant challenge using current synthetic methods. ${ }^{11-14}$ Medicinal chemistry routes to prepare $\mathrm{N}, \mathrm{N}$-diarylsulfonamides analogous to GSK8175 focused on nucleophilic aromatic substitution and low yielding Cu-catalyzed Chan-Lam couplings with aryl boronic acids. ${ }^{10}$ The initial scale-up route to GSK8175 itself relied on a multi-day $\mathrm{S}_{\mathrm{N}} \mathrm{Ar}$ reaction that required the toxic solvent HMPA. Attempts to replace this step with Pd-catalyzed coupling of the secondary mesylaniline to simple aryl halides were unsuccessful, as was sulfonylation of the analogous diarylamine with mesyl chloride. Instead, development focused on optimization of the Chan-Lam approach, employing an aryl boronate ester and a cationic $\mathrm{Cu}$ precatalyst. ${ }^{15,16}$
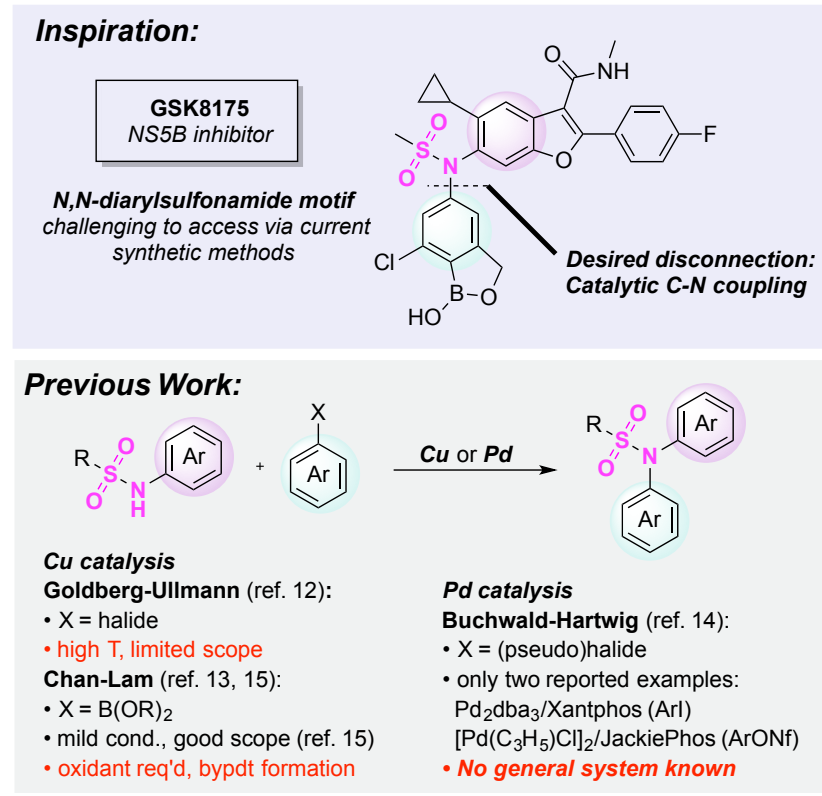

This Work:
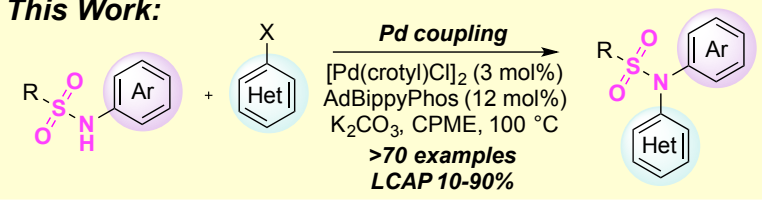

Figure 1. GSK8175, Inspiration for developing C-N bond coupling for synthesis of N,N-diarylsulfonamides; prior catalytic approaches to arylation of $N$-arylsulfonamides; Pd coupling described in the present work. 
The difficulties encountered during this program alerted us to a broader gap in practical synthetic methods for accessing these compounds. A search of the CAS compound database revealed a striking paucity of reported $N, N$-diarylsulfonamides: of the nearly one million reported tertiary sulfonamides, only $\sim 6,000$ have the $N, N$-diaryl substructures shown in Figure 2. We attribute this to the difficulty of $\mathrm{N}$-sulfonylation at a poorly nucleophilic diarylamine, ${ }^{17}$ and the difficulty of arylation at a poorly nucleophilic secondary sulfonamide. Herein we describe a simple yet highly effective palladium/AdBippyPhos catalyst system, which enables access to a wide range of $N, N$-diaryl sulfonamides with pharmaceutically-relevant functionality. We believe this methodology will open unexplored chemical space, and further the development of new potential therapeutics, agrochemicals, and materials.

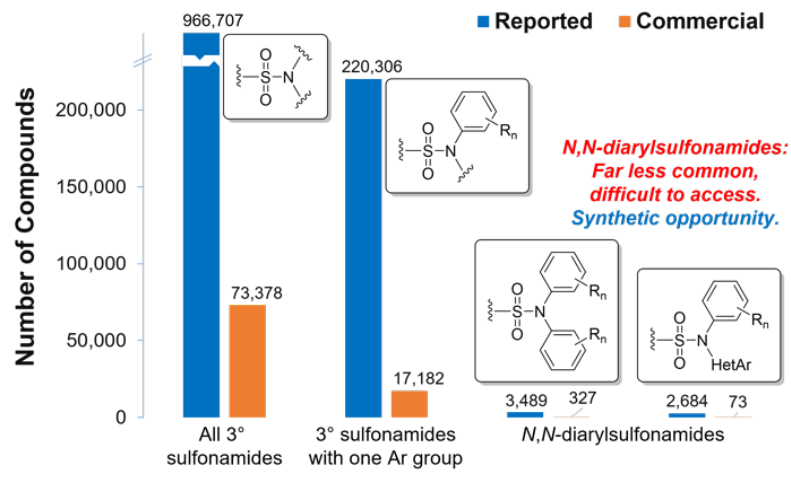

Figure 2. Reported and commercially-available tertiary sulfonamides in the CAS compound database, separated into compound classes.

\section{RESULTS AND DISCUSSION}

We employed high throughput experimentation (HTE) ${ }^{17-}$ 21 to explore the coupling of sulfonamide $\mathbf{1}$ with either aryl bromide $\mathbf{2 a}$ or pyridyl bromide $\mathbf{2 b}$ using a number of $\mathrm{Pd}$ sources, six phosphine ligands (Figure 3), and carbonate bases. ${ }^{22}$ This screen was designed to comprehensively evaluate structural variations of JackiePhos (L1) and BippyPhos (L6), ligands which were found to be the most promising in preliminary trials. L1 is a successful ligand in C-N coupling reactions of amides, ${ }^{14 b}$ JackiePhos variants (L2 and L3) in C$\mathrm{N}$ coupling of hindered amines, ${ }^{23}$ and BippyPhos-type ligands as a broad ligand class for $\mathrm{C}-\mathrm{N}$ coupling reactions. ${ }^{24-29}$ When employing high catalyst loadings (5 mol \% [Pd(crotyl) $\mathrm{Cl}_{2}$ ), all of the ligands screened enabled coupling with aryl bromide 2a; in contrast, only BippyPhos-type ligands enabled appreciable coupling of heteroaryl bromide $\mathbf{2 b}$, with AdBippyPhos (L6) ${ }^{30}$ providing the highest conversion to product (Figure 4). Decreasing the catalyst loading was essential for enabling the practicality of a broad substrate screen in which $>300$ individual substrate combinations were targeted. During attempts to decrease Pd and ligand loadings for larger scale reactions, other ligands failed to promote the coupling reaction (Table 1 ), whereas the reaction of $\mathbf{1}$ ( $1 \mathrm{mmol})$ and $\mathbf{2 b}(1 \mathrm{mmol})$ with $[\mathrm{Pd}(\mathrm{crotyl}) \mathrm{Cl}]_{2}(1$ mol \%) and $\mathbf{L 6}$ ( $4 \mathrm{~mol} \%$ ) resulted in $52 \%$ yield of $\mathbf{3 b}$ (entry 5). Further experiments revealed that adding $3 \AA$ molecular sieves mitigated decomposition of the aryl halide (observed to occur via dehalogenation, hydroxylation, and etherification), leading to a $59 \%$ yield of $\mathbf{3 b}$ (entry 6). ${ }^{14 b, 22}$ Higher yields are obtained when performing the reaction with an excess of aryl halide (vide infra).
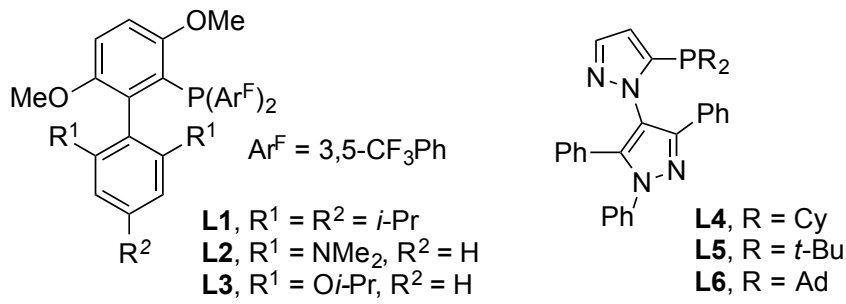

Figure 3. Phosphine ligands screened in high throughput experimentation.

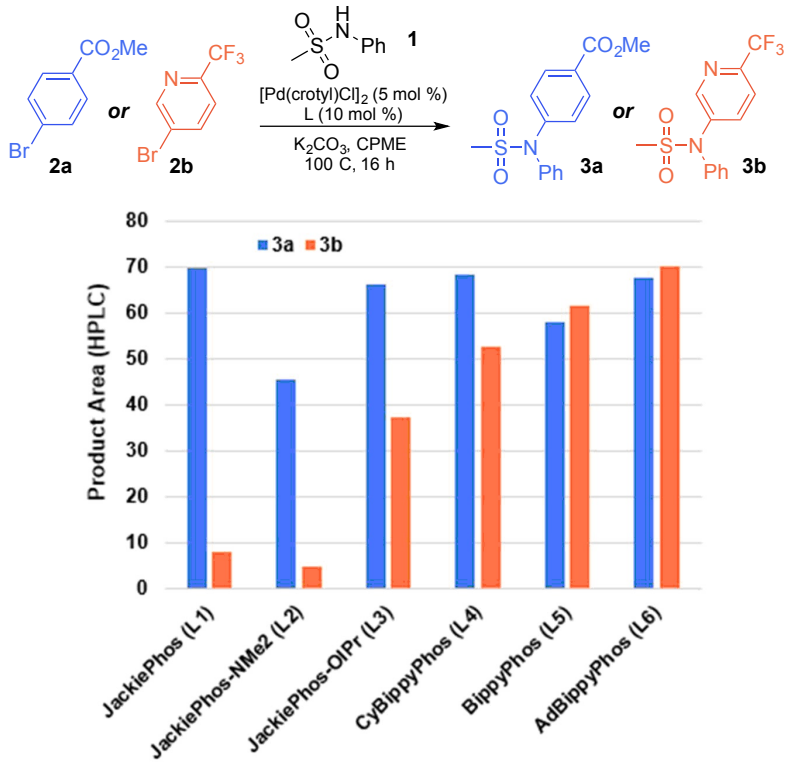

Figure 4. Selected results from high-throughput screening for $\mathrm{N}$-arylation of $\mathrm{N}$-phenylmethanesulfonamide. Reaction conditions: 96-well plate; $0.02 \mathrm{mmol} \mathrm{1,} 0.02 \mathrm{mmol} \mathrm{2,} 0.06 \mathrm{mmol}$ $\mathrm{K}_{2} \mathrm{CO}_{3}, 0.002 \mathrm{mmol}\left[\mathrm{Pd}(\text { crotyl)Cl}]_{2}, 0.008 \mathrm{mmol}\right.$ L1-L6, $0.1 \mathrm{~mL}$ CPME (0.2 M in 1), $100^{\circ} \mathrm{C}$. See SI for full table of results.

Table 1. Dependence of sulfonamide $\mathrm{N}$-arylation on $\mathrm{Pd}$ loading, ligand identity and loading for $1 \mathrm{mmol}$ scale reactions $^{a}$

\begin{tabular}{ccccc} 
Entry & Ligand & $\begin{array}{c}\text { Pd } \\
\text { (mol } \\
\text { \%) }\end{array}$ & $\begin{array}{c}\text { L } \\
\text { (mol } \\
\text { \%) }\end{array}$ & Yield (\%) \\
\hline 1 & BippyPhos (L5) & 5 & 10 & 59 \\
2 & BippyPhos (L5) & 1 & 2 & - \\
3 & AdBippyPhos (L6) & 0.5 & 1 & 6 \\
4 & AdBippyPhos (L6) & 1 & 2 & 14 \\
5 & AdBippyPhos (L6) & 1 & 4 & 52 \\
$6^{b}$ & AdBippyPhos (L6) & 1 & 4 & 59
\end{tabular}

$a$ Reaction conditions: $1 \mathrm{mmol} \mathrm{1,} 1 \mathrm{mmol} \mathrm{2,} 3 \mathrm{mmol} \mathrm{K}_{2} \mathrm{CO}_{3}$, $[\mathrm{Pd}(\text { crotyl }) \mathrm{Cl}]_{2}, \mathbf{L 5}$ or L6, CPME $(0.2 \mathrm{M}), 100^{\circ} \mathrm{C}$. Yield is determined by LC-MS. $b 3 \AA \AA$ molecular sieves are used. 

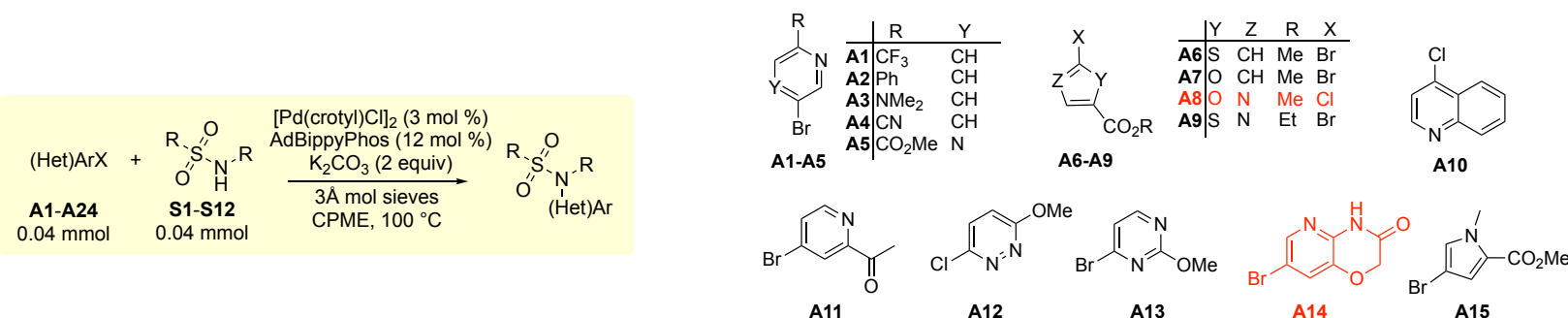

\begin{tabular}{|c|cccccccc|}
\hline & $\mathbf{S 1}$ & $\mathbf{S 2}$ & $\mathbf{S 3}$ & $\mathbf{S 4}$ & $\mathbf{S 6}$ & $\mathbf{S 9}$ & $\mathbf{S 1 0}$ & $\mathbf{S 1 1}$ \\
A1 & 69 & 28 & 25 & 0 & 0 & 32 & 0 & 22 \\
A2 & 83 & 29 & 16 & 0 & 74 & 69 & 0 & 68 \\
A3 & 14 & 5 & 0 & 0 & 17 & 22 & 0 & 31 \\
A4 & 71 & 26 & 12 & 0 & 7 & 13 & 0 & 55 \\
A5 & 78 & 19 & 31 & 0 & 45 & 48 & 23 & 13 \\
A6 & 29 & 0 & 0 & 0 & 5 & 59 & 0 & 75 \\
A7 & 72 & 36 & 15 & 0 & 67 & 0 & 0 & 72 \\
A9 & 75 & 0 & 0 & 0 & 72 & 0 & 0 & 79 \\
A10 & 55 & 8 & 7 & 0 & 20 & 30 & 0 & 75 \\
A11 & 76 & 0 & 0 & 0 & 28 & 0 & 0 & 71 \\
A12 & 34 & 1 & 3 & 24 & 16 & 13 & 0 & 0 \\
A13 & 10 & 0 & 0 & 0 & 6 & 38 & 11 & 0 \\
A15 & 0 & 0 & 0 & 0 & 7 & 16 & 0 & 3 \\
A19 & 0 & 0 & 0 & 0 & 5 & 0 & 0 & 33 \\
A20 & 6 & 0 & 0 & 0 & 5 & 0 & 0 & 24 \\
A21 & 90 & 6 & 33 & 0 & 73 & 18 & 7 & 78 \\
A22 & 0 & 6 & 0 & 0 & 9 & 0 & 0 & 56 \\
A23 & 61 & 12 & 7 & 0 & 41 & 66 & 3 & 44 \\
A24 & 85 & 42 & 11 & 0 & 76 & 36 & 0 & 80 \\
\hline
\end{tabular}
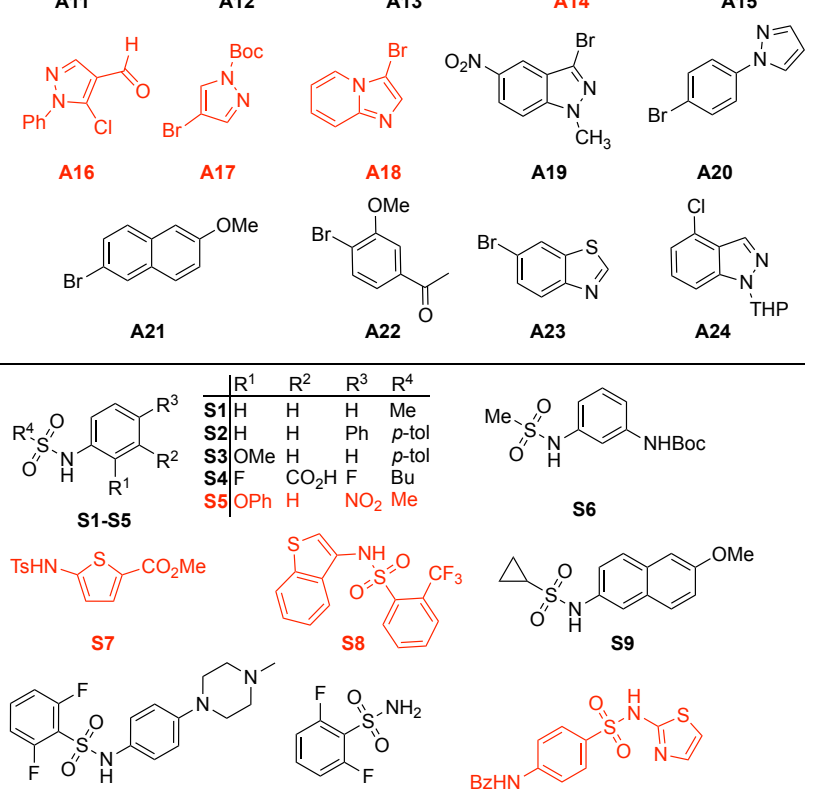

S10
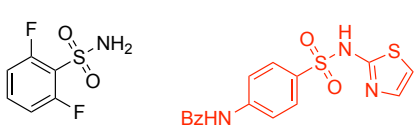

S11

S12

Figure 5. Selected results from evaluation of aryl halides (A1-A24) and sulfonamides (S1-S12) in microscale array experiments. See ESI for details. Left: Values represent the LC area percent of various sulfonamide/aryl halide combinations. Reaction conditions: 0.04 mmol aryl halide, $0.04 \mathrm{mmol}$ sulfonamide, 0.08 mmol K $\mathrm{CO}_{3}$, $3 \AA ̊$ mol sieves, $\left[\mathrm{Pd}(\text { crotyl)Cl}]_{2}\right.$ (3 mol \%), L6 (12 mol \%), $0.5 \mathrm{~mL} \mathrm{CPME,}$ $100{ }^{\circ} \mathrm{C}, 1000 \mathrm{rpm}$ tumble stirring. Right: Compounds in red gave no desired products under any conditions. Sulfonamide S8 undergoes direct arylation at $\mathrm{C} 2$ of the benzothiophene instead of $N$-arylation. ${ }^{22}$

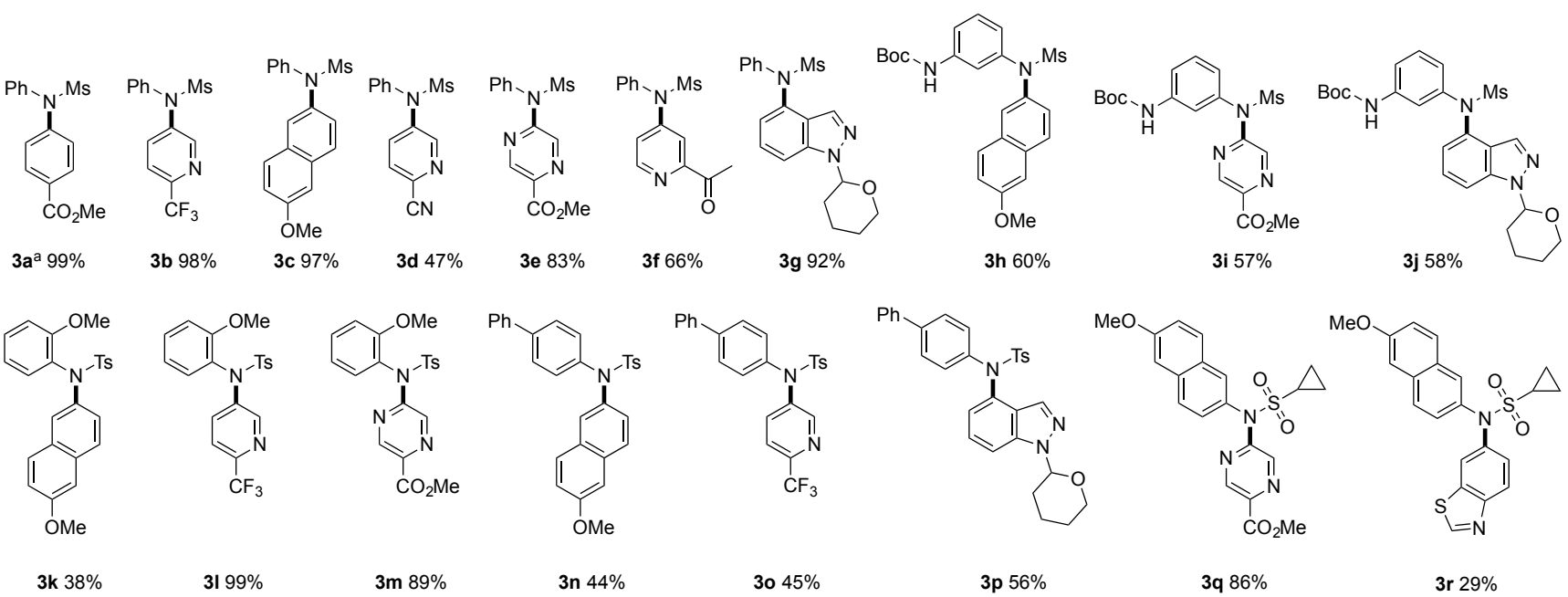

Figure 6. Tertiary sulfonamides isolated by preparative HPLC. Yield corresponds to solution yield versus 1,3,5-trimethoxybenzene by comparison to ${ }^{1} \mathrm{H}$ NMR spectrum of purified material. Reaction conditions: $0.4 \mathrm{mmol}$ aryl halide, $0.2 \mathrm{mmol}$ sulfonamide, $0.6 \mathrm{mmol}$ $\mathrm{K}_{2} \mathrm{CO}_{3}, 3 \AA$ mol sieves, [Pd(crotyl)Cl] 2 (3 mol \%), $\mathbf{L 6}(12 \mathrm{~mol} \%), 0.75 \mathrm{~mL} \mathrm{CPME,} 100{ }^{\circ} \mathrm{C}, 1000 \mathrm{rpm}$ tumble stirring. aReaction conditions: $4 \mathrm{mmol}$ aryl halide, $2 \mathrm{mmol}$ sulfonamide, $6 \mathrm{mmol} \mathrm{K} \mathrm{CO}_{3}, 3 \AA$ mol sieves, $[\mathrm{Pd}$ (crotyl)Cl] 2 (1 mol \%), L6 (4 mol \%), $10 \mathrm{~mL} \mathrm{CPME,}$ $100{ }^{\circ} \mathrm{C}$, yield corresponds to isolated yield. 
A microscale array was designed to evaluate the $[\mathrm{Pd}$ (crotyl) $\mathrm{Cl}_{2} / \mathbf{L} \mathbf{6}$ catalyst system against a large number of substrate combinations (Figure 5). The sulfonamides (S1-S12) were selected to reflect a variety of $S$ - and $N$-substituents, and different steric and electronic properties. One primary sulfonamide (S11) was included for comparison. The heteroaryl halides (A1-A24) were sourced from the GSK compound library to form a diverse set of pharmaceutically-relevant heterocyclic structures. ${ }^{31}$ The reaction outcome was evaluated by LC-MS analysis; the presence of cross-coupled products was initially assessed by MS, and the area percent of the corresponding LC peak (LCAP) provides a semi-quantitative metric of reaction performance.

The microscale array enabled us to survey $>280$ substrate combinations and identify potential targets for preparativescale reactions. In particular, we wished to rapidly determine the viability of different heterocyclic structures which are ordinarily challenging in $\mathrm{C}-\mathrm{N}$ coupling reactions. ${ }^{32,33}$ High yielding reactions $(>50 \%$ LCAP coupling product) were observed with six-membered heterocycles (such as substituted pyridines and pyrazines), five-membered heterocycles (such as furans, thiazoles, and thiophenes), and fused heterocycles (such as quinolones, azindoles, and benzothiazoles). In total, 70 of these microscale reactions resulted in $>10 \%$ LCAP of cross-coupled product. Within the substrate sets, only five of the 24 aryl halides and four of the 12 sulfonamides failed to give any products in the array. Several of these are substrates containing five-membered azoles (A8, A16-18, S12), which remain challenging for many Pd-catalyzed reactions.

To confirm the viability of this method for practical synthesis, a representative set of sulfonamide products was isolated on preparative scale $(0.2 \mathrm{mmol}$ to $2 \mathrm{mmol})$ (Figure 6). Product 3a is formed quantitatively using the optimized conditions, giving excellent isolated yield at lower Pd loading ( 2 mmol 1, 4 mmol 2, 2 equiv $\mathrm{K}_{2} \mathrm{CO}_{3}, 1 \mathrm{~mol} \%$ [Pd(crotyl)Cl] 2, 4 mol \% L6, $3 \AA ̊$ mol sieves, $0.2 \mathrm{M} \mathrm{CPME,} 100{ }^{\circ} \mathrm{C}, 2 \mathrm{~h}$ ). 3b-3s were synthesized on a 10 -fold smaller scale $(0.2$ mmol 1, 0.4 mmol 2, 2 equiv $\mathrm{K}_{2} \mathrm{CO}_{3}, 3 \mathrm{~mol} \%[\mathrm{Pd}(\text { crotyl }) \mathrm{Cl}]_{2}$, $12 \mathrm{~mol} \%$ L6, $3 \AA \AA$ mol sieves, $0.2 \mathrm{M} \mathrm{CPME}, 100^{\circ} \mathrm{C}, 24 \mathrm{~h}$ ) and isolated by mass-directed preparative HPLC. $N$-arylation proceeds chemoselectively in the presence of a tert-butylcarbamate-protected $\mathrm{N}-\mathrm{H}$ bond (3h-3k) as indicated by NMR analysis. ${ }^{22}$ High yields of products with ortho-substituted $\mathrm{N}$-arylsulfonamides can be obtained using these conditions (3k-3m), though sulfonamides with less electronrich S-substituents (3n-3p) generally result in lower yields (i.e., $S$-Tol versus $S$-Me).

Having found bipyrazolylbis(alkyl)phosphine-based ligands are more effective than conventional biarylbis(alkyl)phosphine or biarylbis(aryl)phosphine ligands for the arylation of secondary sulfonamides, we turned to steric modelling using DFT optimized geometries (PBE0/6$\left.31+\mathrm{g}^{*}\right)$ in order to identify specific ligand features that are correlated with high-yield couplings. The steric character of palladium-phosphine complexes is determined using methods developed by Guzei and coworkers ${ }^{34}$ and previously used by Sigman. ${ }^{35}$ Relevant features derived from the maximum-cone angle conformations are shown in Table 2. Of the ligands investigated in our initial screens (Fig. 4), those able to promote the synthesis of $\mathbf{3 b}$ in $>50 \%$ solution yield all have estimated cone angles (ECAs) $>195^{\circ}$; however, those that give the highest solution yields also result in comparatively lower $\mathrm{G}(\mathrm{Pd})$ - which is defined as the percentage the $\mathrm{Pd}$ center shielded by ligand atoms. ${ }^{34}$ The JackiePhos series (L1-L3, entries 5-7) features progressively larger cone angles and lower G(Pd) values, and within the BippyPhos series (L5, entry 3 and L6, entry 1 ) exhibit large cone angles $\left(196-210^{\circ}\right)$ and low G(Pd) (19.3-21.4\%).

While further study is required to thoroughly assess this correlation, our working hypothesis is that ligands with a low $\mathrm{G}(\mathrm{Pd})$ provide a binding pocket for the weakly coordinating sulfonamide substrates, while a large ligand cone angle promotes the challenging $\mathrm{C}-\mathrm{N}$ reductive elimination through remote steric pressure. ${ }^{36}$ Prior work has implicated both $N$-metallation and reductive elimination as potentially rate-limiting for $\mathrm{Pd}$-catalyzed $\mathrm{C}-\mathrm{N}$ couplings of amides and sulfonamides. ${ }^{17,37-39}$ Thus, while previous catalyst development efforts focused on generating a more electron-deficient $\mathrm{Pd}$ center to improve amide/sulfonamide binding ${ }^{17}$ and reductive elimination, ${ }^{40}$ we propose that steric effects are likely to be critical in expanding the scope of this coupling reaction.

Table 2. Steric parameters for biaryl and bis(pyrazolyl) phosphine ligands.

\begin{tabular}{cccc} 
Entry & Ligand & $\mathrm{ECA}^{\mathrm{a}}\left({ }^{\circ}\right)$ & $\mathrm{G}(\mathrm{Pd})^{\mathrm{b}}(\%)$ \\
\hline 1 & AdBippyphos (L6) & 209.7 & 19.34 \\
2 & AdBrettPhos & 217.9 & 24.56 \\
3 & Bippyphos (L5) & 202.7 & 20.78 \\
4 & CyBippyphos (L4) & 195.8 & 21.40 \\
5 & JackiePhos (L1) & 163.4 & 19.34 \\
6 & JackiePhos-NMe 2 & 193.7 & 19.35 \\
7 & (L2) & 190.5 & 20.60 \\
8 & JackiePhos-OiPr (L3) & 173.0 \\
9 & Me4BuXPhos & 175.5 & 28.00 \\
10 & tBuXPhos & 205.8 & 24.78 \\
aECA = Estimated Cone Angle. bG(Pd) $\%$ Pd shielded \\
by ligand atoms.
\end{tabular}

\section{CONCLUSION}

We have identified a superior Pd catalyst system for challenging $N$-arylations of secondary sulfonamides. While several ligands are suitable for the synthesis of simple tertiary sulfonamides, AdBippyPhos (L6) is particularly adept at installing pharmaceutically-relevant heteroaromatic moieties. By using an array of microscale experiments, we were able to simultaneously determine the catalyst's amenability to different heterocyclic electrophiles and various sulfonamide structures. Compatible heterocycles include substituted pyridines, pyrazines, thiazoles, thiophenes, furans, benzothiazoles, and azindoles, while five-membered $\mathrm{N}$-containing heterocycles such as pyrroles or pyrazoles remain challenging. A number of tertiary sulfonamide products have been isolated on $0.2-2 \mathrm{mmol}$ scale in good to excellent 
yields. We propose that the success of $\mathbf{L 6}$ is related to specific steric properties, as evidenced by the large ECA and G(Pd) determined through the steric modelling of Pd-phosphine complexes. This interplay of ligand cone angle and $\mathrm{G}(\mathrm{Pd})$ provide a set of criteria for evaluating new potential ligand scaffolds for sulfonamide arylations; work to test this hypothesis is currently underway.

\section{ASSOCIATED CONTENT}

\section{Supporting Information}

The Supporting Information is available free of charge on the ACS Publications website.

Experimental procedures, CAS structure search results, characterization, computational methods, chromatographic and spectral data. (PDF)

\section{AUTHOR INFORMATION}

\section{Corresponding Author}

* E-mail for G.E.D.: dob@temple.edu

* E-mail for D.C.L.: dcleitch@uvic.ca

\section{Notes}

The authors declare no competing financial interests.

\section{ACKNOWLEDGMENT}

This work was supported by the National Science Foundation (CHE-1565721). Support for the NMR facility at Temple University by a CURE grant from the Pennsylvania Department of Health is gratefully acknowledged.

\section{REFERENCES}

1) Roughley, S. D.; Jordan, A. M. The Medicinal Chemist's Toolbox: An Analysis of Reactions Used in the Pursuit of Drug Candidates. J. Med. Chem. 2011, 54, 3451-3479.

2) Scott, K. A.; Njardarson, J. T. Analysis of US FDA-Approved Drugs Containing Sulfur Atoms. Top. Curr. Chem. 2018, 376, 5.

3) Das, P.; Delost, M. D.; Qureshi, M. H.; Smith, D. T.; Njardarson, J. T. A Survey of the Structures of US FDA Approved Combination Drugs. J. Med. Chem. 2019, 62, 4265-4311.

4) Zhao, C.; Rakesh, K. P.; Ravidar, L.; Fang. W.-Y.; Qin, H.-L. Pharmaceutical and medicinal significance of sulfur ( $\mathrm{S}^{\mathrm{VI}}$ Containing motifs for drug discovery: A critical review. Eur. J. Med. Chem. 2019, 162, 679-734.

5) Hansch, C.; Sammes, P. G.; Taylor, J. B: Comprehensive Medicinal Chemistry, Vol. 2, Pergamon Press: Oxford 1990.

6) Rakesh, K. P.; Wang, S. M.; Leng, J.; Ravindar, L.; Asir, A. M.; Marwani, H. M.; Qin, H.-L. Recent Development of Sulfonyl or Sulfonamide Hybrids as Potential Anticancer Agents: A Key Review. Anti-Cancer Agents Med Chem. 2018, 18, 488505.

7) Mehelloy, Y.; De Clercq, E. Twenty-Six Years of Anti-HIV Drug Discovery: Where Do We Stand and Where Do We Go? J. Med. Chem. 2010, 53, 521-538.

8) Gardner, S. D.; Kim, J.; Baptiste-Brown, S.; Lopez, V.; Hamatake, R.; Gan, J.; Edwards, S.; Elko-Simms, L.; Dumont, E. F.; Leivers, M.; Hong, Z.; Paff, M. T. GSK2878175, a pan-genotypic non-nucleoside NS5B polymerase inhibitor, in healthy and treatment-naïve chronic hepatitis C subjects. J. Viral Hepat. 2018, 25, 19-27.

9) Devendar, P.; Wang, G. F. Sulfur-containing Agrochemicals. Top. Curr. Chem. 2017, 375, 375-382.

10) a) Chong, P. Y.; Miller, J. F.; Peat, A. J.; Shotwell, J. B. Benzofuran compounds for the treatment of hepatitis $c$ virus infections, W02013028371A1, 28 February 2013. b) Chong, P. Y.; Shotwell, B.; Miller, J.; Price, D. J.; Maynard, A.; Voitenlieter, C.; Mathis, A.; Williams, S.; Pouliot, J. J.; Creech, K.; Wang, F.; Peat, A. J. Design of N-Benzoxaborole Benzofuran GSK8175-Optimization of Human Pharmacokinetics Inspired by Metabolites of a Failed Clinical HCV Inhibitor. J. Med. Chem. 2019, 62, 3254-3267.

11) Scozzafava, A.; Carta, F.; Supuran, C. T. Secondary and Tertiary Sulfonamides: A Patent Review (2008-2012). Expert Opin. Ther. Pat. 2013, 23, 203-213.

12) For Goldberg-Ullmann coupling examples, see: a) Coutts, G. C.; Hamblin, M. Synthesis of N,N-diaryltoluene-4-sulphonamides J. Chem. Soc., Perkin Trans. 1 1975, 2445-2446. b) Raposo, M. M. M.; Pereira, A. M. B.; Oliveira-Campos, A. M. F.; Shannon, P. V. R. Synthesis of highly substituted diphenylacetamides and diphenylsulfonamides by the Goldberg coupling reaction J. Chem. Research (S) 2000, 156-158. c) Majumdar, K. C.; Ganai, S. CuI/L-Proline-Catalyzed Intramolecular Aryl Amination: An Efficient Route for the Synthesis of 1,4-Benzodiazepinones. Synlett 2011, 1881-1887. d) Geng, X.; Mao, S.; Chen, L.; Yu, J.; Han, J.; Hua, J.; Wang, L. Copper-catalyzed direct $\mathrm{N}$-arylation of $\mathrm{N}$-arylsulfonamides using diaryliodonium salts in water. Tetrahedron Lett. 2014, 55, 3856-3859.

13) For Chan-Lam coupling examples, see: a) Chan, D. M. T.; Monaco, K. L.; Wang, R.-P.; Winters, M. P. New N- and O-arylations with phenylboronic acids and cupric acetate. Tetrahedron Lett. 1998, 39, 2933-2936. b) Demont, E. H.; Redshaw, S.; Walter, D. S. Hydroxyethylamine compounds having sp2 inhibitory activity for the treatment of alzheimer's disease, WO2004080376A2, 23 September 2004. c) Eickmeier, C.; Fuchs, K.; Peters, S.; Dorner-Ciossek, C.; Handschuh, N. H. S.; Klinder, K.; Kostka, M. Substituted 1,2-ethylendiamines, medicaments comprising said compound; their use and their method of manufacture, W02006103038A1, 5 October 2006.

14) For Pd-catalyzed coupling examples, see: a) $\mathrm{Wu}, \mathrm{Y}$.-J.; Zhang, Y.; Good, A. C.; Burton, C. R.; Toyn, J. H.; Albright, C. F.; Macor, J. E.; Thompson, L. A. Synthesis and SAR of hydroxyethylamine based phenylcarboxyamides as inhibitors of BACE. Bioorg. Med. Chem. Lett. 2009, 19, 2654-2660. b) Hicks, J. D.; Hyde, A. M.; Martinez Cuezva, A.; Buchwald, S. L. Pd-Catalyzed N-Arylation of Secondary Acyclic Amides: Catalyst Development, Scope, and Computational Study. J. Am. Chem. Soc. 2009, 131, 16720-16734.

15) Vantourout, J. C.; Li, L.; Mendito-Moll, E.; Chabbra, S.; Arrington, K.; Bode, B. E.; Isidrio-Llobet, A.; Kowalski, J. A.; Nilson, M. G.; Wheelhouse, K. M. P.; Woodard, J. L.; Xie, S.; Leitch, D. C.; Wilson, A. J. B. Mechanistic Insight Enables Practical, Scalable, Room Temperature Chan-Lam N-Arylation of N-Aryl Sulfonamides. ACS Catal. 2018, 8, 9560-9566.

16) Arrington, K.; Barcan, G. A.; Calandra, N. A.; Erickson, G. A.; Li, L.; Liu, L.; Nilson, M. G.; Strambeanu, I. I.; VanGelder, K. F.; Woodard, J. L.; Xie, S.; Allen, C. L.; Kowalski, J. A.; Leitch, D. C. Convergent Synthesis of the NS5B Inhibitor GSK8175 Enabled by Transition Metal Catalysis. J. Org. Chem. 2019, 84, 4680-4694.

17) Mennen, S. M.; Alhambra, C.; Allen, C. L. Barberis, M.; Berritt, S.; Brandt, T. A.; Campbell, A. D.; Castañón, J.; Cherney, A. H.; Christensen, M.; Damon, D. B.; de Diego, J. E.; García-Cerrada, S.; García-Losada, P.; Haro, R.; Janey, J.; Leitch, D. C.; Li, L.; Liu, F.; Lobben, P. C.; MacMillan, D. W. C.; Magano, J.; McInturff, E.; Monfette, S.; Post, R. J.; Schultz, D.; Sitter, B. J.; 
Stevens, J. M.; Strambeanu, I. I.; Twilton, J.; Wang, K.; Zajac, M. A. The Evolution of High-Throughput Experimentation in Pharmaceutical Development and Perspectives on the Future. Org. Process Res. Dev. 2019, 23, 1213-1242.

18) Allen, C. L.; Leitch, D. C.; Anson, M. S.; Zajac, M. A. The power and accessibility of high-throughput methods for catalysis research. Nature Catal. 2019, 2, 2-4.

19) Shevlin, M. Practical High-Throughput Experimentation for Chemists. ACS Med. Chem. Lett. 2017, 8, 601-607.

20) Wei, S. M.; Simmons, E. M.; Hsaio, Y.; Eastgate, M. G. Development of Robust, Scaleable Catalytic Processes through Fundamental Understanding of Reaction Mechanisms. Top. Catal. 2017, 60, 620-630.

21) Isbrandt, E. S.; Sullivan, R. J.; Newman, S. G. High Throughput Strategies for the Discovery and Optimization of Catalytic Reactions. E. S. Isbrandt, R. J. Sullivan, S. G. Newman, Angew. Chem., Int. Ed. 2018, 58, 7180-7191.

22) See supporting information for details.

23) Park, N. H.; Vinogradova, E. V.; Surry, D. S.; Buchwald, S. L. Design of New Ligands for the Palladium-Catalyzed Arylation of $\alpha$-Branched Secondary Amines. Angew. Chem., Int. Ed. 2015, 54, 8259-8262.

24) Singer, R. A.; Dore, M.; Sieser, J. E.; Berliner, M. A. Development of nonproprietary phosphine ligands for the Pd-catalyzed amination reaction. Tetrahedron Lett. 2006, 47, 3727-3731.

25) Withbroe, G. J.; Singer, R. A.; Sieser, J. E. Streamlined Synthesis of the Bippyphos Family of Ligands and Cross-Coupling Applications.Org. Process Res. Dev. 2008, 123, 480489

26) Crawford, S. M.; Lavery, C. B.; Stradiotto, M. BippyPhos: A Single Ligand With Unprecedented Scope in the BuchwaldHartwig Amination of (Hetero)aryl Chlorides. Chem. Eur. J. 2013, 19, 16760-16761.

27) Brusoe, A. T.; Hartwig, J. F. Palladium-Catalyzed Arylation of Fluoroalkylamines. J. Am. Chem. Soc. 2015 137, 84608468.

28) Lavery, C. B.; Rotta-Loria, N. L.; MacDonald, R.; Stradiotto, M. $\mathrm{Pd}_{2} \mathrm{dba}_{3} /$ Bippyphos: A Robust Catalyst System for the Hydroxylation of Aryl Halides with Broad Substrate Scope. Adv. Synth. Catal. 2013, 355, 981-987.

29) Strotman, N. A.; Soumeillant, M. C.; Zhu, K.; Markwalter, C. E.; Wei, C. S.; Hsaio, Y.; Eastgate, M. D. Effects of Multiple Catalyst Deactivation Pathways and Continuous Ligand Recycling on the Kinetics of Pd-Catalyzed C-N Coupling Reactions. J. Org. Chem. 2019, 84, 4653-4660.
30) Gowrisankar, S.; Sergeev, A. G.; Anarasan, P.; Spannenberg, A.; Neumann, H.; Beller, M. A General and Efficient Catalyst for Palladium-Catalyzed C-O Coupling Reactions of Aryl Halides with Primary Alcohols. J. Am. Chem. Soc. 2010, 132, 11592-11598.

31) Kutchukian, P. S.; Dropinski, J. F.; Dykstra, K. D.; Li, B.; DiRocco, D. A.; Streckfuss, E. C.; Campeau, L.-C.; Cernak, T.; Vachal, P.; Davies, I. W.; Krska, S. W.; Dreher, S. D. Chemistry informer libraries: a chemoinformatics enabled approach to evaluate and advance synthetic methods. Chem. Sci. 2016, 7, 2604-2613.

32) Su, M.; Buchwald, S. L. A Bulky Biaryl Phosphine Ligand Allows for Palladium-Catalyzed Amidation of Five-Membered Heterocycles as Electrophiles. Angew. Chem., Int. Ed. 2012, $51,4710-4713$.

33) Su, M.; Hoshiya, N.; Buchwald, S. L. Palladium-Catalyzed Amination of Unprotected Five-Membered Heterocyclic Bromides. Org. Lett. 2014, 16, 832-835.

34) Guzei, I. A.; Wendt, A. An improved method for the computation of ligand steric effects based on solid angles. Dalton Trans. 2006, 33, 3991-3999.

35) Niemeyer, Z. L.; Milo, A.; Hickey, D. P.; Sigman, M. S. Parameterization of phosphine ligands reveals mechanistic pathways and predicts reaction outcomes. Nature Chem. 2016, 8, 610-617.

36) For an example in Ni-catalysis where remote steric effects enhance reactivity, see: Wu, K.; Doyle, A. G. Parameterization of phosphine ligands demonstrates enhancement of nickel catalysis via remote steric effects. Nature Chem. 2017, 9, 779-784.

37) Shen, Q.; Hartwig, J. F. Lewis Acid Acceleration of C-N BondForming Reductive Elimination from Heteroarylpalladium Complexes and Catalytic Amidation of Heteroaryl Bromides. J. Am. Chem. Soc. 2007, 129, 7734-7735.

38) Ikawa, T.; Barder, T. E.; Biscoe, M. R.; Buchwald, S. L. PdCatalyzed Amidations of Aryl Chlorides Using Monodentate Biaryl Phosphine Ligands: A Kinetic, Computational, and Synthetic Investigation. J. Am. Chem. Soc. 2007, 129, 1300113007.

39) Becica, J.; Dobereiner, G. E. Acceleration of Pd-Catalyzed Amide N-Arylations Using Cocatalytic Metal Triflates: Substrate Scope and Mechanistic Study. ACS Catal. 2017, 7, 5862-5870.

40) Arrechea, P. L.; Buchwald, S. L. Biaryl Phosphine Based Pd(II) Amido Complexes: The Effect of Ligand Structure on Reductive Elimination. J. Am. Chem. Soc. 2016, 138, 1248612493.

\section{Insert Table of Contents artwork here}

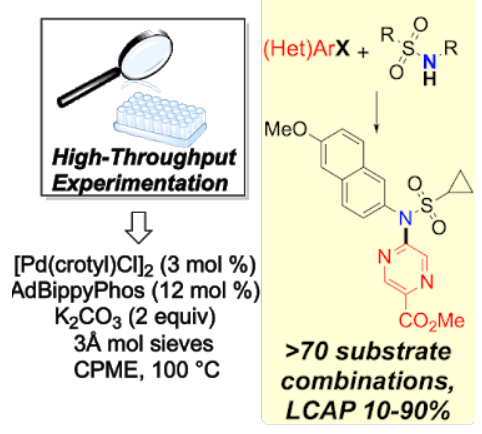

